\title{
Determination of Carbon Isotope Ratios in Amino Acids, Proteins, and Oligosaccharides by Inductively Coupled Plasma-Mass Spectrometry
}

\author{
Elise T. Luong* and R. S. Houk \\ Department of Chemistry, Ames Laboratory, United States Department of Energy, Iowa State University, Ames, \\ Iowa, USA
}

Carbon isotope ratios $\left({ }^{12} \mathrm{C} /{ }^{13} \mathrm{C}\right)$ are measured for aqueous solutions of tryptophan, myoglobin, and $\beta$-cyclodextrin using $\mathrm{C}^{+}$ions from an inductively coupled plasma (ICP) and a prototype twin quadrupole mass spectrometer (MS). ${ }^{13} \mathrm{C} /{ }^{12} \mathrm{C}$ ratios can be determined with a relative standard deviation (RSD) of $\sim 1 \%$. This precision is close to the limiting value predicted by counting statistics $(1.16 \%)$. Spectral interference on ${ }^{13} \mathrm{C}^{+}$, presumably from ${ }^{12} \mathrm{C}^{1} \mathrm{H}^{+}$, comes from the incomplete dissociation of myoglobin and/or $\beta$-cyclodextrin, but not tryptophan. Decreasing the aerosol gas flow rate slightly from that which yields maximum signal eliminates this ${ }^{12} \mathrm{C}^{1} \mathrm{H}^{+}$interference. The count rate of the minor isotope $\left({ }^{13} \mathrm{C}^{+}\right)$can be artificially enhanced by increasing the voltage of the ${ }^{13} \mathrm{C}^{+}$detector, and/or by shifting the ion beam splitter offset from the central axis. Instrumental modifications to the MS that improve the sensitivity are also described. (J Am Soc Mass Spectrom 2003, 14, 295-301) (C) 2003 American Society for Mass Spectrometry

I nductively coupled plasma mass spectrometry (ICPMS) is a versatile technique for elemental and isotopic analysis. Applications of ICP-MS range from elemental determinations to isotopic analysis in nutrition, clinical studies, geochemistry, environmental studies, and the semiconductor and nuclear industries. ICP-MS has long linear dynamic range (eight orders of magnitude) and detection limits at part per trillion levels for many elements. Most ICP-MS instruments contain a quadrupole or magnetic sector mass spectrometer with a single detector. These are sequential devices that do not measure the various $m / z$ values of interest at precisely the same time. They provide moderate to good precision in isotope ratio measurements, typically $0.05 \%$ relative standard deviation (RSD) on ratios close to unity, with substantially poorer precision on large or small ratios [1-4].

Much of the instability in the ion signal is caused by flicker noise from the ICP. This source of noise can be eliminated by measuring the various $m / z$ values at the same time using a multicollector magnetic sector device $[5,6]$. We have described a unique instrument with two quadrupole mass filters and an ion beam splitter that

Published online March 10, 2003

Address reprint requests to Dr. R. S. Houk, Department of Chemistry, Ames Laboratory, United States Department of Energy, Iowa State University, Ames, IA 50011, USA. E-mail: rshouk@iastate.edu

*Present address: National Institutes of Health, National Human Genome Research Institute, Bethesda, MD 20892, USA. also eliminates the flicker noise contribution to isotope ratios [7]. Allen and co-workers have analyzed solid copper and steel samples using laser ablation with this twin quadrupole device. The isotope ratio precision reported by Allen et al. was 0.06 to $0.1 \%$ for ${ }^{52} \mathrm{Cr} /{ }^{53} \mathrm{Cr}$, depending on the dwell time and averaging method used [8].

This paper evaluates the performance obtained for measurement of carbon isotope ratios from organic compounds at natural isotopic abundance. The ultimate goal is to provide a method for carbon isotopic analyses in bioorganic molecules in aqueous solution. This is an ambitious goal, since carbon is only 1 to $5 \%$ ionized in the ICP [9]. Thus, the sensitivity (i.e., count rate per unit concentration) is much lower than that for the metals and metalloids usually determined by ICP-MS, and ${ }^{13} \mathrm{C}$ is only $\sim 1 \%$ of ${ }^{12} \mathrm{C}$. No more than $0.1 \%$ of the analyte ions in the plasma are eventually detected, so the overall efficiency of ICP-MS for $\mathrm{C}^{+}$is expected to be low.

Thus, ICP-MS has not been widely used for measurements of carbon. Vogl and Heumann [10, 11] found

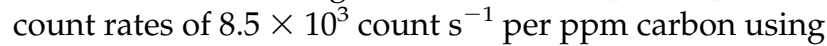
a conventional quadrupole ICP-MS. They determined dissolved organic carbon using isotope dilution, in both the overall solution and in fulvic and humic acid fractions separated by chromatography. The precision of the ${ }^{13} \mathrm{C} /{ }^{12} \mathrm{C}$ ratio measurements at natural isotopic 


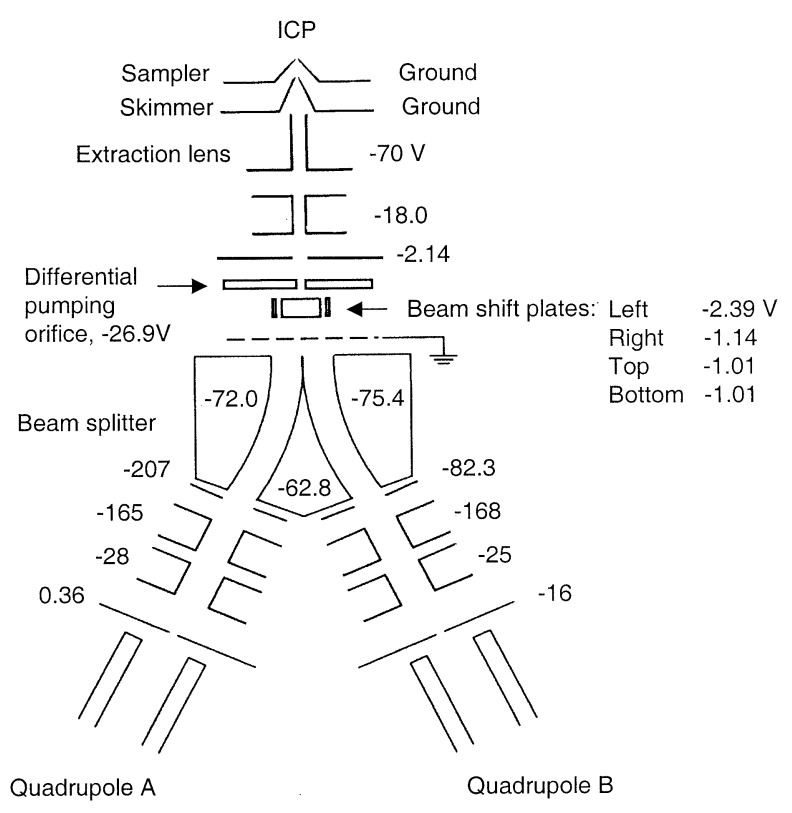

Figure 1. Diagram of the twin quadrupole mass spectrometer.

abundance was $\sim 3 \%$ relative standard deviation (RSD) at carbon concentrations of $\sim 50 \mathrm{ppm}$.

The potential advantages of ICP-MS for determining carbon isotope ratios are (a) the carbon isotopes are measured using atomic $\mathrm{C}^{+}$ions rather than molecular ions like $\mathrm{CO}_{2}^{+}$, which require corrections for $\mathrm{O}$ isotopes, (b) aqueous solutions of nonvolatile biological compounds can be analyzed directly without combustion or derivatization, provided the analyte compound is the only substance that contains carbon, (c) sample solutions can be changed quickly with very low memory effects or cross contamination. This is a feasibility study. It is realized that the precision and sensitivity will not be as good as that obtained using well-established, proven methods such as GC combustion isotope ratio MS, which can achieve RSDs as good as $0.001 \%$ [12-20].

\section{Experimental}

\section{Instrumentation}

The home built ICP twin quadrupole MS is shown in Figure 1. The main components have been described previously $[7,8]$. Standard operating conditions are listed in Table 1.

The heart of this instrument is the ion beam splitter (Figure 1), which consists of two $30^{\circ}$ toroidal electrostatic analyzers back to back. The ion beam from the ICP is extracted through the sampler and skimmer, passes through a series of ion lenses and beam shift plates, and is then divided into two parts at the entrance of the splitter. Each part travels through one side of the splitter to its own quadrupole mass analyzer and detector. Ions at two individual $\mathrm{m} / \mathrm{z}$ values can be measured separately and simultaneously. Most of the flicker noise from the ICP and sample introduction system
Table 1. General operating conditions

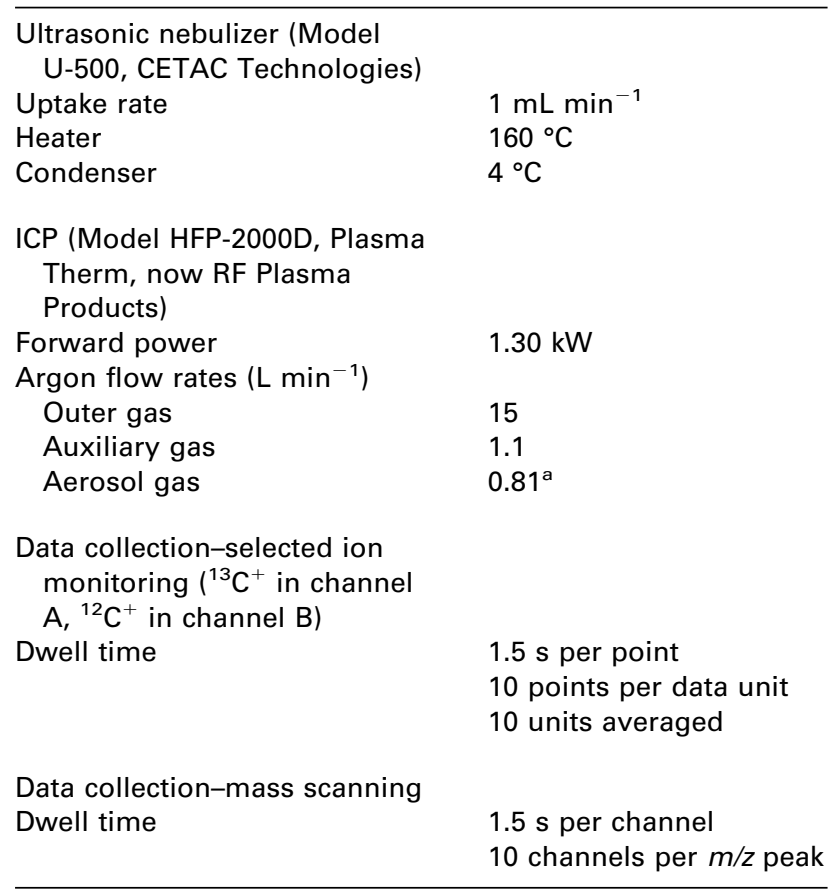

${ }^{a} 0.88$ initially, see Table 3 and accompany text.

cancels when the ratio is calculated. Note that the beam is split before it is mass analyzed. Thus, some analyte ions are lost in the splitter, and the sensitivity will be lower than that of either a scanning instrument or a multicollector based on a magnetic sector [8].

Typical ion lens voltages are also listed in Figure 1. The first extraction lens and the beam shift plates are the most important lenses. The left and right beam shift plate voltages determine the fraction of the ion beam sent to each channel. The voltages of the three electrodes of the splitter and the alignment of the splitter also influence the portion of the beam sent to each channel. These voltages are optimized daily to achieve the best precision for isotope ratio measurements.

As a result, the ion beam is often split unequally between the two channels. Sometimes, the ion beam is split more to channel A than channel B and vice versa. Consequently, the measured isotopic ratio differs from the natural abundance ratio, and a calibration curve for the relative sensitivity of each channel is needed. This will be discussed in more detail in the Results and Discussion section. Throughout this paper, the terms channel A and channel B refer to the sides of the instrument that contain quadrupole $\mathrm{A}$ and quadrupole B, as shown in Figure 1.

\section{Modifications}

The sampler-skimmer separation was changed from 8 $\mathrm{mm}$ to $10 \mathrm{~mm}$ for normal operation. The second stage differential pumping orifice (Figure 1) was enlarged from $1.5 \mathrm{~mm}$ to $2 \mathrm{~mm}$ in diameter. An additional ion lens (1.5 mm long) was placed behind the second 
extraction lens and in front of the differential pumping plate. A series of extension lenses with different lengths $(0.5,0.75$, and $1.25 \mathrm{~cm})$ but with the same inner diameter of $1.5 \mathrm{~cm}$ were made of stainless steel and used to adjust the skimmer-first extraction lens separation. The skimmer mounting flange was also modified to accommodate a commercial skimmer (aperture $0.82 \mathrm{~mm}$ diameter, PE Sciex ELAN 6000, Concord, Ontario, Canada). Finally, the ions were detected with discrete dynode electron multipliers (Model AF 562A, ETP Scientific, Auburn, MA) rather than Channeltrons.

\section{Materials and Reagents}

A 5-mL Teflon sample loop (Alltech, Deerfield, IL, USA) was installed between the peristaltic pump and the ultrasonic nebulizer. This sample loop reduced background noise and rinse out time, compared to that obtained by drawing the samples through a peristaltic pump, especially for the protein and carbohydrate solutions. Deionized water was produced by a Millipore Laboratory Water System (Bedford, MA) with an organics pyrogen-free system, consisting of one super-C carbon cartridge, two ion-exchange cartridges, and two organex-Q cartridges. Solutions were prepared and stored in 15 or $50 \mathrm{~mL}$ polypropylene tubes (Fisher Scientific, Pittsburgh, PA). Particulates were filtered from the amino acid and protein solutions using $5 \mathrm{~mL}$ syringes and $45 \mu \mathrm{m}$ filters, also supplied by Fisher Scientific.

Ultrex II ultra-pure concentrated nitric acid was purchased from J. T. Baker (Phillipsburg, NJ). Lithium working solutions were diluted from the stock $1000 \mathrm{mg}$ $\mathrm{L}^{-1}$ ICP standard (Plasmachem, Farmingdale, NJ). A $10,000 \mathrm{mg} \mathrm{L}^{-1}$ stock solution of $\alpha$-D-glucose (hereafter simply called glucose, Aldrich, Milwaukee, WI) was prepared in deionized $\mathrm{H}_{2} \mathrm{O}$. Working solutions of 1000 ppm $\beta$-cyclodextrin were prepared by dissolution of the solid $\beta$-cyclodextrin (Fluka, Ronkonkoma, NY). Lyophilized tryptophan and horse heart myoglobin were obtained from Sigma (St. Louis, MO). All working solutions were prepared prior to use by diluting stock solutions with deionized $\mathrm{H}_{2} \mathrm{O}$, except for tryptophan, which was dissolved in aqueous $\mathrm{HNO}_{3}$ at $\mathrm{pH}=4$.0. The ${ }^{13} \mathrm{C} /{ }^{12} \mathrm{C}$ ratio in these "natural abundance" solutions was assumed to be 0.111 , the usual quoted value. Enriched ${ }^{13} \mathrm{C}$ glucose was purchased from Cambridge Isotope Laboratories (Andover, MA), dissolved into a stock solution, and added to these natural abundance solutions in known volumes.

\section{Drift and Background Correction}

Slow instrumental drift usually occurs in ICP-MS devices. The individual count rates drift more severely than the ratio. Drift in the twin quadrupole device complicates the isotope ratio measurements. After the calibration curve is established at the beginning of the day, the isotopic standard is analyzed periodically, and a normalization factor $\mathrm{K}$ is used to correct for drift during data processing. $\mathrm{K}$ is defined as the measured ${ }^{13} \mathrm{C} /{ }^{12} \mathrm{C}$ ratio at later time $\mathrm{t}$ divided by the measured ${ }^{13} \mathrm{C} /{ }^{12} \mathrm{C}$ ratio at initial time $\mathrm{t}=0$ when the calibration curve was constructed. The natural abundance glucose solution is usually analyzed to determine $\mathrm{K}$, although any of the eight enriched standards could be used. The measured ${ }^{13} \mathrm{C} /{ }^{12} \mathrm{C}$ ratio $\left(\mathrm{R}_{\mathrm{m}}\right)$ from protein or carbohydrate samples is then multiplied by this factor $\mathrm{K}$ to yield a new ${ }^{13} \mathrm{C} /{ }^{12} \mathrm{C}$ ratio called $\mathrm{R}_{\mathrm{m}}{ }^{\prime}$. $\mathrm{R}_{\mathrm{m}}{ }^{\prime}$ is used in place of $R_{m}$ for the calculation of the actual ratio using the daily beam splitter calibration curve. The calculated ratios $R$ and the corresponding calibration curves comprise the data reported below. The $\mathrm{K}$ values remained within the range 0.97 to 1.03 .

Background is measured at $m / z=12$ and 13 during nebulization of deionized water. The average background count rates are substantial, about 4000 counts $\mathrm{s}^{-1}$ and 300 counts $\mathrm{s}^{-1}$ at $m / z=12$ and 13 , in general agreement with the observations of Vogl and Heumann $[10,11]$. These background values are subtracted from the gross count rates from the samples. Isotope signals and ratios are calculated using these net count rates.

\section{Results and Discussion}

\section{Sensitivity Improvement}

Carbon is not efficiently ionized in a typical "hot" ICP [8]. Light ions pass through the supersonic expansion with low kinetic energy and are thus more vulnerable to space charge effects than heavy ions, which also hurts sensitivity for $\mathrm{C}^{+}$. Use of a "cool" plasma [21-24] improves sensitivity for light, easily ionized elements like $\mathrm{Li}^{+}$but is not an option for elements with high ionization energies (IE) like $\mathrm{C}(\mathrm{IE}=11.26 \mathrm{eV})$.

To improve sensitivity for $\mathrm{C}^{+}$, ion extraction parameters such as type of skimmer and distance between skimmer and extraction lens were varied systematically. The rationale for these experiments is described separately [25]. Lithium, a convenient element near the molar mass of carbon, was monitored in this part of the study. Essentially, the sensitivity improves as the extraction lens is moved closer to the skimmer, as found previously in our laboratory for a similar homemade extraction device [26]. Replacing the homemade skimmer with the Sciex skimmer also improved sensitivity. Combining these alterations led to an overall sensitivity improvement of a factor of 19 [25]. The eventual sensitivity achieved, $4.2 \times 10^{6} \mathrm{c} \mathrm{s}^{-1}$ per ppm Li, is still well below that obtainable by conventional instruments. It is believed that many ions are lost at or inside the beam splitter. Improved design of this component could probably improve sensitivity further.

\section{Initial Results}

The ICP is ignited and all electronics are warmed up for at least one hour. The ICP operating conditions are 

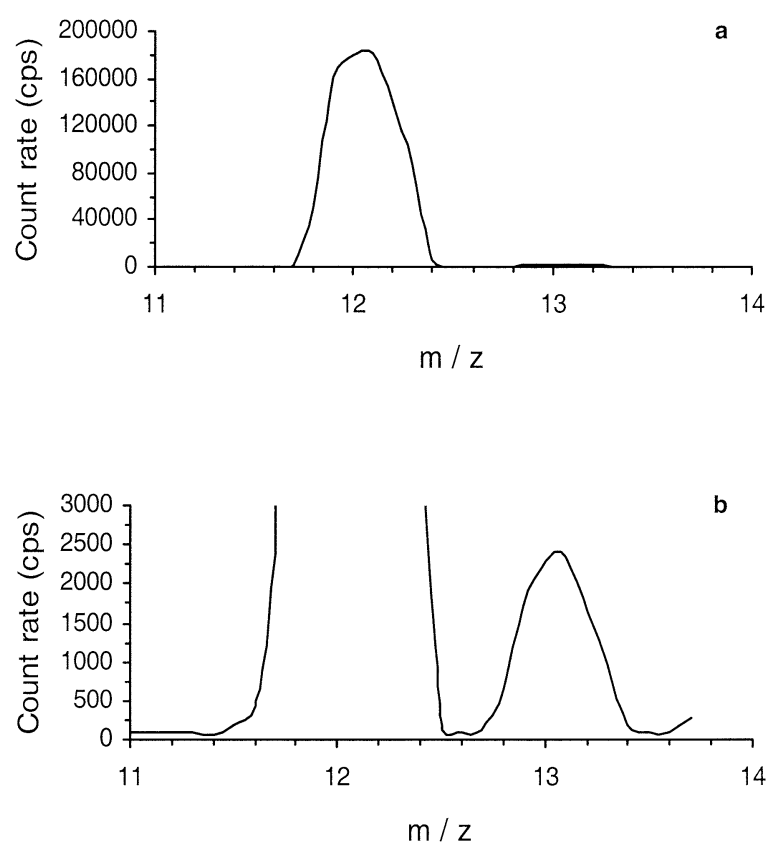

Figure 2. Mass spectrum of $\mathrm{C}^{+}$ions from $1000 \mathrm{ppm}$ glucose in $\mathrm{H}_{2} \mathrm{O}$.

adjusted to maximize sensitivity for $\mathrm{Li}^{+}$. The instrument is then fine-tuned with a natural abundance glucose standard. The aerosol gas flow rate is adjusted to maximize count rate for ${ }^{12} \mathrm{C}^{+}$on both channels $\mathrm{A}$ and B. Lastly, the voltages of the beam shift plates are adjusted for best precision in the ${ }^{13} \mathrm{C} /{ }^{12} \mathrm{C}$ ratio.

A typical mass spectrum of $\mathrm{C}^{+}$, obtained by scanning one of the mass analyzers, is shown in Figure 2. On an expanded scale (Figure $2 b$ ), the peak at $\mathrm{m} / \mathrm{z} 13$ shows up clearly and is baseline resolved from those at $\mathrm{m} / \mathrm{z} 12$ and 14. A calibration curve for ${ }^{13} \mathrm{C}$ is linear $(\mathrm{y}=429.7 \mathrm{x}+$ $\left.278.2, r^{2}=0.9997\right)$. Figure 3a shows typical rinse out curves for both $\mathrm{C}^{+}$isotopes. Signals from both channels rinse out simultaneously in less than $2 \mathrm{~min}$. A correlation plot determined from the entire rinse out curves is linear with $r^{2}=0.9995$ (Figure $3 b$ ). Thus, the signals in the two channels remain correlated even as the $C$ source is rinsing out of the sample introduction system. The molar sensitivity for ${ }^{13} \mathrm{C}^{+}$in Channel $\mathrm{A}$ is deliberately made greater than that for ${ }^{12} \mathrm{C}^{+}$in Channel $\mathrm{B}$.

Table 2 summarizes typical results for measurements of ${ }^{12} \mathrm{C}^{+}$and ${ }^{13} \mathrm{C}^{+}$from glucose at natural abundance on five different days. Each value is the average of 100 data points from the same day with one quadrupole at $\mathrm{m} / \mathrm{z}=$ 13 , and the other quadrupole at $m / z=12$. In general, the RSD of the ratios is better than the RSD of the individual signals, as expected. To be fair, the RSD should be compared to that expected from counting statistics, i.e., the shot noise limit. [The shot noise limit to the isotope ratio precision is given by $s_{R} / R=\left(1 / I_{12}+1 / I_{13}\right)^{1 / 2}$, where $s_{R}$ is the standard deviation of ratio $R$ and $I$ are the integrated counts for the indicated isotope per integration cycle. For the small ratios usually measured in this work, the precision is determined largely by the
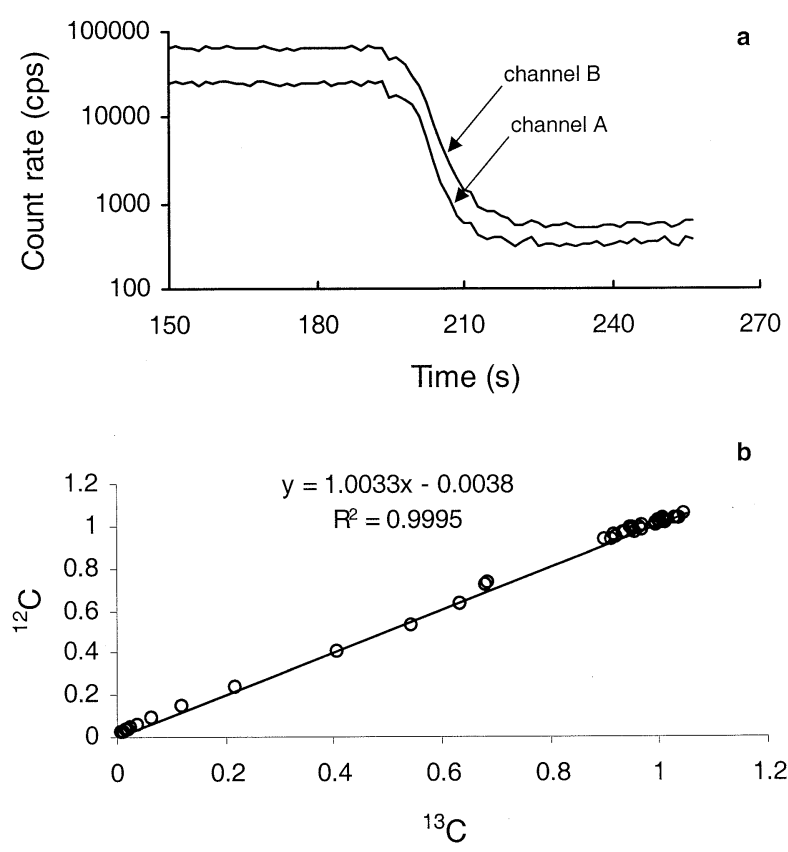

Figure 3. (a) Rinse out curves for $\mathrm{C}^{+}$from $500 \mathrm{ppm}$ glucose in deionized $\mathrm{H}_{2} \mathrm{O}$ enriched with equal amount of ${ }^{13} \mathrm{C}$-glucose. Count rates at channel $\mathrm{A}$ and channel $\mathrm{B}$ were monitored simultaneously at $m / z=13$ and $m / z=12$, respectively. The sample was removed and replaced with blank at about $190 \mathrm{~s}$. (b) Correlation plot from (a), a plot of normalized count rate of ${ }^{12} \mathrm{C}$ at channel $\mathrm{B}$ versus the normalized count rate of ${ }^{13} \mathrm{C}$ at channel $\mathrm{A}$.

standard deviation of ${ }^{13} \mathrm{C}^{+}$, the less abundant ion.] Although ${ }^{13} \mathrm{C}$ is only $\sim 1 \%$ of ${ }^{12} \mathrm{C}$, isotope ratios with count rate ratios as great as $58 / 1$ can be measured with precision only $50 \%$ lower than that expected just from counting statistics.

\section{Isotope Ratio Calibration}

The measured ${ }^{13} \mathrm{C} /{ }^{12} \mathrm{C}$ ratios in Table 2 are different from the natural abundance ratio (0.0111) and also vary from day to day. The bias is substantial due to the different transmission of each side of the beam splitter and each mass analyzer and the different response of each detector. The measured ratios are therefore calibrated against known ratios in standard solutions spiked with glucose enriched in ${ }^{13} \mathrm{C}$ (Figure 4). The least squares fit of these eight points of the calibration curve shows the square of the correlation coefficient is essentially unity, and the intercept approaches zero. The slope of the line reflects the split ratio of the system. The steeper the slope, the more the measured ratio deviates from the actual ratio. Figure 4 illustrates the results obtained with the voltages adjusted to provide a split ratio of approximately 2.5/1. Even in an extreme case where the split ratio is $\sim 12 / 1$, meaning 12 parts of the ion beam were directed to one channel and only one part of the beam was sent to the other channel, the calibration curve is still linear $\left(y=12.04 x+0.1131, \mathrm{r}^{2}=\right.$ 0.9996).

This is a unique and potentially useful characteristic 
Table 2. Raw, uncalibrated carbon isotope ratio measurements on glucose, $1000 \mathrm{mgL}^{-1}$

\begin{tabular}{lll}
\hline $\begin{array}{l}{ }^{13} \mathrm{C}^{+} \text {Count rate, } \\
\% \text { RSD }\end{array}$ & $\begin{array}{c}{ }^{12} \mathrm{C}^{+} \text {Count rate, } \\
\% \text { RSD }\end{array}$ & $\begin{array}{c}{ }^{3} \mathrm{C} /{ }^{12} \mathrm{C} \text { Ratio, } \\
\% \text { RSD }\end{array}$ \\
\hline \hline $3372,1.75 \%$ & $188000,2.62 \%$ & $0.0180,1.65 \%$ \\
$5079,3.67$ & $269000,4.40$ & $0.0189,0.91$ \\
$3860,1.11$ & $165000,1.26$ & $0.0233,1.32$ \\
$3550,0.96$ & $197000,1.76$ & $0.0171,1.42$ \\
$3230,2.67$ & $87700,5.51$ & $0.0388,1.22$ \\
\hline
\end{tabular}

of the ion beam splitter for measuring very large or very small isotope ratios. A smaller portion of the ion beam can be used to measure the more abundant isotope and a bigger portion of the ion beam for measuring the less abundant isotope. In this fashion, the count rate of the major isotope is sacrificed to improve the count rate and counting statistics for the minor isotope. The altered isotope ratio can easily be related to the actual ratio with a calibration curve, which is necessary anyway. The calibration curves are always linear from day to day although the slopes and intercepts may vary. The mean square correlation coefficient $\left(\mathrm{r}^{2}\right)$ from six calibration curves is $0.9996 \pm 0.0002( \pm \mathrm{SD})$.

\section{Plasma Optimization and Removal of ${ }^{12} \mathrm{C}^{1} \mathrm{H}^{+}$}

Initial results were measured for tryptophan and myoglobin at natural isotopic abundance. Calibration curves

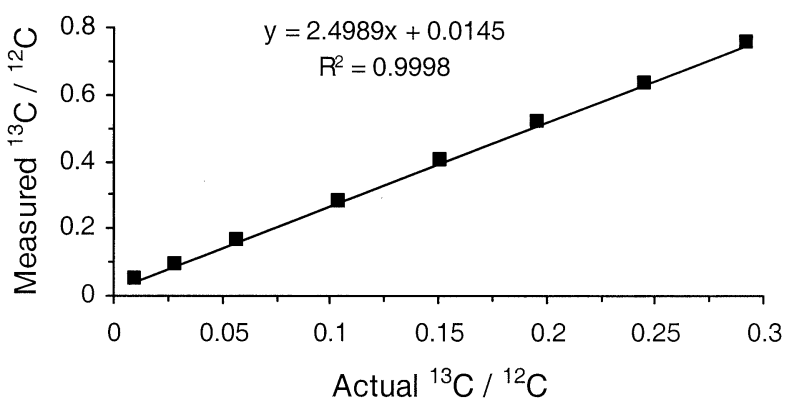

Figure 4. Calibration curve for isotope ratios. Standard 1000 ppm glucose solutions at natural abundance were spiked with different amounts of ${ }^{13} \mathrm{C}$-glucose. The horizontal axis represents the actual ${ }^{13} \mathrm{C} /{ }^{12} \mathrm{C}$ ratios after spiking. The vertical axis is the ${ }^{13} \mathrm{C} /{ }^{12} \mathrm{C}$ ratio measured by ICP-MS. The uncertainty of each point is smaller than the symbol. Split ratio is $\sim 2.5 / 1$. were based on enriched glucose isotopic standards with plasma conditions optimized to provide maximum signal. The expected ${ }^{13} \mathrm{C} /{ }^{12} \mathrm{C}$ ratio after calibration was 0.0111. Measured ratios from tryptophan were perhaps a little low $(0.0109 \pm 0.004$ and $0.0107 \pm 0.0001$ on different days), while those from myoglobin were definitely too high $(0.0120 \pm 0.0002$ and $0.0129 \pm 0.0001)$.

A high result for the ${ }^{13} \mathrm{C} /{ }^{12} \mathrm{C}$ ratio suggests a spectral interference at $m / z=13$, presumably ${ }^{12} \mathrm{C}^{1} \mathrm{H}^{+}$. The IE of $\mathrm{CH}$ is $10.64 \mathrm{eV}$, which is just $0.62 \mathrm{eV}$ below the IE of carbon $(11.26 \mathrm{eV})$. The dissociation energy of $\mathrm{C}^{+}-\mathrm{H}$ is $4.08 \mathrm{eV}$ [27]. These values are comparable to those of other polyatomic ions seen from the ICP $[28,29]$, and theoretical calculations of the abundance ratio indicates some ${ }^{12} \mathrm{C}^{1} \mathrm{H}^{+}$could survive in the plasma [25]. The variation of the observed ratios for the different compounds suggests that the ${ }^{12} \mathrm{C}^{1} \mathrm{H}^{+}$interference was worst for myoglobin, moderate for glucose, and minimal for tryptophan [25]. Globular proteins such as myoglobin retain water especially strongly. The protein nanoparticles produced by the nebulizer and desolvator may not be fully dried, which would increase the density of $\mathrm{H}$ atoms in the plasma and enhance formation of $\mathrm{CH}^{+}$ from mass action considerations.

The results of experiments to attenuate the interference from ${ }^{12} \mathrm{C}^{1} \mathrm{H}^{+}$are shown in Table 3. Unlike the other isotope ratio results, these were obtained by scanning one channel of the mass analyzer. The mass bias introduced by the beam splitter should thus be negligible. In order to dry the aerosol more thoroughly, the heater temperature of the desolvator was increased to $160{ }^{\circ} \mathrm{C}\left(20{ }^{\circ} \mathrm{C}\right.$ higher than normal) for all these measurements.

In the first set of results in Table 3, the plasma

Table 3. Effect of ICP-MS operating parameters on apparent carbon isotope ratios from glucose, $1000 \mathrm{mg} \mathrm{L}^{-1}$

\begin{tabular}{|c|c|c|c|c|c|}
\hline $\begin{array}{l}\text { Extraction lens } \\
\text { voltage (volts) }\end{array}$ & $\begin{array}{c}\text { Forward power } \\
(\mathrm{kW})\end{array}$ & 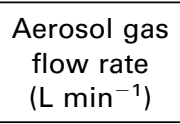 & $\begin{array}{c}{ }^{12} \mathrm{C}^{+} \text {count rate } \\
\left(\times 10^{3}\right), \mathrm{RSD}\end{array}$ & $\begin{array}{c}\text { Apparent }{ }^{13} \mathrm{C}^{+} /{ }^{12} \mathrm{C}^{+} \\
\text {ratio from mass } \\
\text { scanning }\end{array}$ & $\begin{array}{r}\text { Relative } \\
\text { error \% } \\
\end{array}$ \\
\hline-150 & 1.30 & 0.882 & $532,3.6 \%$ & $\begin{array}{l}0.0126 \pm 0.0002 \\
(n=7)\end{array}$ & 13.3 \\
\hline-150 & 1.30 & 0.834 & $370,3.3 \%$ & $\begin{array}{l}0.0117 \pm 0.0003 \\
(n=6)\end{array}$ & 5.2 \\
\hline-150 & 1.25 & 0.834 & $432,2.4 \%$ & $\begin{array}{l}0.0114 \pm 0.0003 \\
(n=7)\end{array}$ & 2.5 \\
\hline-150 & 1.30 & 0.810 & $656,3.0 \%$ & $\begin{array}{l}0.0112 \pm 0.0002 \\
(n=7)\end{array}$ & 0.7 \\
\hline-170 & 1.30 & 0.810 & $1213,3.8 \%$ & $\begin{array}{l}0.0111 \pm 0.0003 \\
(n=5)\end{array}$ & 0.02 \\
\hline
\end{tabular}


Table 4. Carbon isotope ratio measurements for myoglobin and $\beta$-cyclodextrin; plasma conditions adjusted to minimize $\mathrm{CH}^{+}$ interference

\begin{tabular}{lccc}
\hline $\begin{array}{l}\text { Myoglobin }{ }^{13} \mathrm{C} /{ }^{12} \mathrm{C} \text { ratio, } \\
\text { RSD\% }\end{array}$ & $\begin{array}{c}\text { Counting stats } \\
\text { RSD\% }\end{array}$ & $\begin{array}{c}\beta \text {-cyclodextrin }{ }^{13} \mathrm{C} /{ }^{12} \mathrm{C} \text { ratio, } \\
\text { RSD } \%\end{array}$ & $\begin{array}{c}\text { Counting stats } \\
\text { RSD\% }\end{array}$ \\
\hline \hline $0.0110,1.64$ & 1.65 & $0.0115,0.97$ & 1.40 \\
$0.0107,1.80$ & 1.65 & $0.0111,1.40$ & 1.66 \\
$0.0114,1.82$ & 1.66 & $0.0110,1.32$ & 1.48 \\
$0.0104,1.52$ & 1.66 & $0.0112,2.02$ & 1.40 \\
$0.0109 \pm 0.0004^{*}$ & & $0.0109,1.88$ & 1.40 \\
\hline
\end{tabular}

Cal. curve $y=1.3802 x+0.4446 r^{2}=0.9996$

*Mean \pm SD.

conditions are selected to maximize $\mathrm{Li}^{+}$signal, and the ${ }^{13} \mathrm{C} /{ }^{12} \mathrm{C}$ ratio is 0.0126 , too high. The ratio creeps closer to the expected value of 0.0111 as aerosol gas flow rate decreases and/or power increases.

These changes in ICP conditions affect the characteristics of the region in the plasma where the ions are sampled. Typically, if plasma parameters are set to maximize signal, the initial radiation zone (IRZ) [30] ends just upstream from the tip of the sampler. The IRZ is fairly sharply defined when a dry aerosol is introduced [31]. The IRZ moves further upstream (i.e., away from the sampling orifice) as power increases and aerosol gas flow rate decreases. The zone sampled would be expected to be slightly "hotter" and atomization should be more extensive under these conditions. The bottom entries for $\mathrm{C}^{+}$count rate in Table 3 show that increasing the extraction lens voltage more than compensates for the signal lost by adjusting aerosol gas flow rate to suppress $\mathrm{CH}^{+}$.

\section{${ }^{13} \mathrm{C} /{ }^{12} \mathrm{C}$ Measurements in Myoglobin and Cyclodextrin}

Results obtained under conditions optimized as described above to remove $\mathrm{CH}^{+}$are shown in Table 4. The averaged ratio values are $0.0109 \pm 0.0004$ and $0.0111 \pm$ 0.0002 , not appreciably different from the expected value of 0.0111 . In other experiments (data not shown), whether the myoglobin sample was dissolved in deionized water or in dilute nitric acid did not affect the measured ratios [25]. The ${ }^{13} \mathrm{C} /{ }^{12} \mathrm{C}$ ratio from myoglobin was also measured by mass scanning and found to be 0.0112 , in agreement with the values obtained by single ion monitoring. The observed precision values were in the range 1.4 to $1.8 \%$ RSD. These precision values are close to those expected from counting statistics, being worse by only 10 to $50 \%$.

\section{Conclusion}

Measurements of carbon isotope ratios from solutions of non-volatile bio-organic compounds have been demonstrated with our prototype inductively coupled plasma twin quadrupole device. At present, the precision is $\sim 1 \%$ RSD, which is sufficient for many stable carbon isotope metabolic tracer and labeling studies. Obvious improvements include the use of a multicollector magnetic sector MS, new micronebulizers to reduce the amount of sample required, improved sensitivity, and reduced $\mathrm{C}^{+}$levels from the blank. In the latter area, Vogl and Heumann reduced the $\mathrm{C}^{+}$background by about a factor of three by acidifying the samples and purging them with helium, indicating much of the $\mathrm{C}$ background is $\mathrm{CO}_{2}$ dissolved in the sample [11]. It may be possible to reduce the $\mathrm{C}^{+}$blank by removing carbon compounds from the argon. Note also that interference from $\mathrm{Mg}^{2+}$ is possible on both C isotopes, so it is important to be sure the sample does not contain appreciable $\mathrm{Mg}$.

With these developments, ICP-MS could develop into an alternative method to GC-MS and GC-combustion-IRMS for rapid carbon isotope ratio determinations. Because the mass analyzers are not scanned, the method could also be valuable for carbon isotope ratio measurements during transient signals such as LC peaks, although exclusion of other carbon sources such as organic solvents or buffer compounds would be necessary.

\section{Acknowledgments}

This research was supported by the U.S. Department of Energy, Office of Basic Energy Sciences, through the Ames Laboratory (Contract no. W-7405-Eng-82). The authors thank CETAC Technologies (ultrasonic nebulizer), Marc Porter (glucose and deionized water), and Jacob Petrich (horse heart myoglobin). Robert Serfass and Richard Kniseley confirmed the purity of the nitric acid and deionized water. Ho Ming Pang and Alexandre Smirnov helped modify the data acquisition software.

\section{References}

1. Begley, I.; Sharp, B. L. Occurrence and Reduction of Noise in ICP-MS for Enhanced Precision in Isotope Ratio Measurement. J. Anal. Atomic Spectrom. 1994, 9, 171-176.

2. Furuta, N. Optimization of Mass Scanning Rate for Determination of Lead Isotope Ratios Using an ICP-MS. J. Anal. Atomic Spectrom. 1991, 6, 199-207.

3. Ketterer, M. E.; Peters, M. J.; Tisdale, P. J. Verification of a Correction Procedure for Measurement of $\mathrm{Pb}$ Isotope Ratios by ICPMS. J. Anal. Atomic Spectrom. 1991, 6, 439-443. 
4. Whittaker, P. G.; Barrett, J. F. R.; Williams, J. G. J. Anal. Atomic Spectrom. $1992,7,109$.

5. Walder, A. J.; Koller, D.; Reed, N. M.; Hutton, R. C.; Freedman, P. A. Isotope Ratio Measurement by ICP Multicollector MS Incorporating a High Efficiency Nebulization System. J. Anal. Atomic Spectrom. 1993, 8, 1037-1042.

6. Walder, A. J.; Abell, I. D.; Platzner, I.; Freedman, P. A. Lead Isotope Ratio Measurement of NIST 610 Glass by Laser Ablation ICP-MS. Spectrochim. Acta Part B 1993, 48B, 397-402.

7. Warren, A. R.; Allen, L. A.; Pang, H. M.; Houk, R. S.; Janghorbani, M. Simultaneous Measurement of Ion Ratios by ICP-MS with a Twin Quadrupole Instrument. Appl. Spectrosc. 1994, 48, 1360-1366.

8. (a) Allen, L. A.; Pang, H. M.; Warren, A. R.; Houk, R. S. Simultaneous Measurement of Isotope Ratios in Solids by Laser Ablation with a Twin Quadrupole ICP-MS. J. Anal. Atomic Spectrom. 1995, 10, 267-271. (b) Allen, L. A.; Leach, J. J.; Pang, H. M.; Houk, R. S. Precise Measurement of Ion Ratios in Solids Using Laser Ablation ICP-MS with a Twin Quadrupole Instrument. J. Anal. Atomic Spectrom. 1997, 12, 171-176.

9. Houk, R. S. Mass Spectrometry of ICPs. Anal. Chem. 1986, 58, 97A-105A.

10. Vogl, J.; Heumann, K. G. Determination of Heavy Metal Complexes with Humic Substances by HPLC/ICP-MS Using On-line Isotope Dilution Technique. Fresenius J. Anal. Chem. 1997, 359, 438-441.

11. Vogl, J.; Heumann, K. G. Development of an ICP-IDMS Method for Dissolved Organic Carbon Determinations and Its Application to Chromatographic Fractions of Heavy Metal Complexes with Humic Substances. Anal. Chem. 1998, 70, 2038-2043.

12. Sugimoto, A. GC/GC/C/IRMS System for Carbon Isotope Measurement of Low Level Methane Concentration. Geochem. J. 1996, 30, 195-200.

13. Meier-Augenstein, W.; Watt, P. W.; Langhans, C. D. Influence of GC Parameters on Measurement of ${ }^{13} \mathrm{C} /{ }^{12} \mathrm{C}$ Isotope Ratios by GLC/Combustion/Isotope Ratio MS. J. Chromatogr. A. 1996, 752, 233-241.

14. McRae, C.; Love, G. D.; Murray, I. P.; Snape, C. E.; Fallick, A. E. Potential of GC- Isotope Ratio MS to Source Polynuclear Aromatic Hydrocarbon Emission. Anal. Commun. 1996, 33, 331-335.

15. Aguilera, R.; Becchi, M.; Casabianca, H.; Hatton, C. K.; Catlin, D. H.; Starcevic, B.; Pope, H.G., Jr. Improved Method of Detection of Testosterone Abuse by GC/Combustion/Isotope Ratio MS Analysis of Urinary Steroids. J. Mass Spectrom. 1996, 31, 169-176.
16. Abramson, F. P.; Osborn, B. L.; Teffera, Y. Isotopic Differences in Human Growth Hormone Preparations. Anal. Chem. 1996, 68, 1971-1972.

17. Popp, B. N.; Sansone, F. J.; Rust, T. M.; Merritt, D. A. Determination of Concentration and Carbon Isotopic Composition of Dissolved Methane in Sediments and Nearshore Waters. Anal. Chem. 1995, 67, 405-411.

18. Sansone, F. J.; Popp, B. N.; Rust, T. M. Stable Carbon Isotopic Analysis of Low-Level Methane in Water and Gas. Anal. Chem. 1997, 69, 40-44.

19. Matthew, D. E.; Hayes, J. M. Isotope Ratio Monitoring GC-MS. Anal. Chem. 1978, 50, 1465-1473.

20. Brenna, J. T.; Corso, T. N.; Tobias, H. J.; Caimi, R. J. HighPrecision Continuous-Flow Isotope Ratio MS. Mass Spectrom. Reviews 1997, 16, 227-258.

21. Jiang, S.-J.; Stevens, M.; Houk, R. S. Alleviation of Spectral Overlap Interferences for Determination of Isotope Ratios of Potassium by ICP-MS. Anal. Chem. 1988 , 60, 1217.

22. Tanner, S. D. Characterization of Ionization and Matrix Suppression in Inductively Coupled "Cold" Plasma MS. J. Anal. Atomic Spectrom. 1995, 10, 905-921.

23. Sakata, K.; Kawabata, K. Reduction of Fundamental Polyatomic Ions in ICP-MS. Spectrochim. Acta Part B 1994, 49, 1027-1038.

24. Nonose, N. S.; Matsuda, N.; Fudagawa, N.; Kubota, M. Some Characteristics of Polyatomic Ion Spectra in ICP-MS. Spectrochim. Acta Part B 1994, 49, 955-974.

25. Luong, E. T. Ph.D. Thesis, Iowa State University, 1999 pp $71-84$.

26. Hu, K.; Clemons, P. S.; Houk, R. S. Analytical Characteristics of a New, Offset Ion Lens for ICP-MS. I. Ion Trajectories and Detector Performance. J. Am. Soc. Mass Spectrom. 1993, 4, $16-27$.

27. Huber, K. P.; Herzberg, G. Molecular Spectra and Molecular Structure IV. Constants of Diatomic Molecules. Van Nostrand Reinhold: New York, 1979 p 144.

28. Houk, R. S.; Praphairaksit, N. Dissociation of Polyatomic Ions in the ICP. Spectrochim. Acta Part B 2001, 56, 1069-1096.

29. Evans, E. H.; Ebdon, L.; Rowley, L. Comparative Study of the Determination of Equilibrium Dissociation Temperature in ICP-MS. Spectrochim. Acta Part B 2002, 57, 741-747.

30. Koirtyohann, S. R.; Jones, J. S.; Yates, D. A. Nomenclature System of the Low Power ICP. Anal. Chem. 1980, 52, 1965.

31. Houk, R. S.; Winge, R. K.; Chen, X. A High Speed Photographic Study of Wet Droplets and Solid Particles in an ICP. J. Anal. Atomic Spectrom. 1997, 12, 1139-1148. 